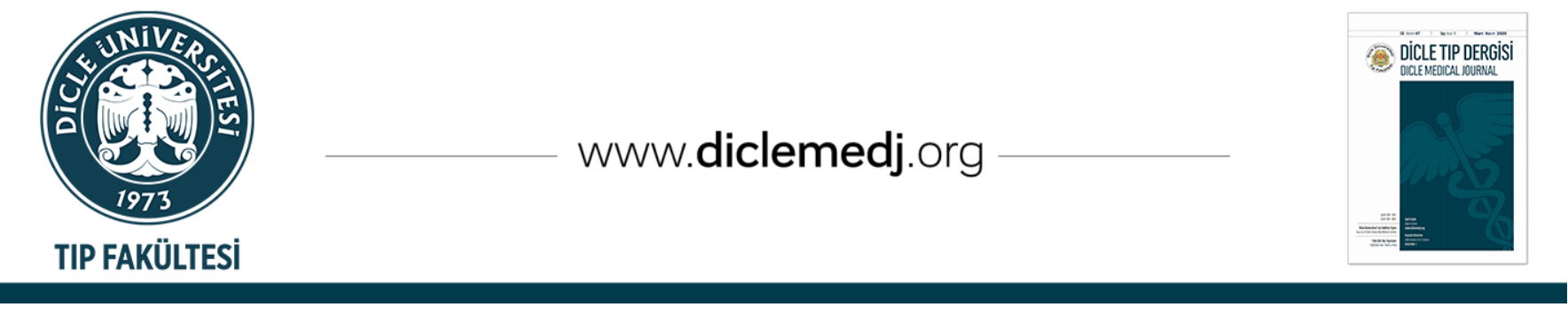

Özgün Araștırma / Original Article

\title{
Nöro-Behçet Hastalığında Klinik Özellikler
}

\author{
Sibel Gazioglu ${ }^{1}$, Merve Boz ${ }^{1}$, Deniz Aksu Arıca (iD) 2, Cavit Boz (D) 1 \\ 1 Karadeniz Teknik Üniversitesi Tıp Fakültesi, Nöroloji Anabilim Dall, 61080 Trabzon, Türkiye \\ 2 Karadeniz Teknik Üniversitesi Tıp Fakültesi, Deri ve Zührevi Hastalıklar Anabilim Dalı, 61080 Trabzon, Türkiye
}

Geliş: 06.03.2020; Revizyon: 01.06.2020; Kabul Tarihi: 02.06.2020

Öz

Giriş: Behçet hastalığında (BH) nörolojik tutulum nadir olsa da, morbiditenin ana nedenlerinden biridir. Bu çalışmada Nöro-Behçet hastalığının (NBH) klinik ve radyolojik özelliklerinin araştırılması amaçlanmıştır.

Yöntemler: Ocak 2011- Aralık 2017 tarihleri arasında nöroloji kliniğinde NBH tanısı alan 22 hastanın demografik ve klinik özellikleri retrospektif olarak gözden geçirilmiştir.

Bulgular: Hastaların yaş ortalaması 39.18 \pm 12.25 olup, erkek/kadın oranı 1 idi. Nörolojik tutulum gelişimine kadar geçen ortalama hastalık süresi $8.95 \pm 4.28$ yıldı. 20 hastada $(\% 90,9)$ parankimal santral sinir sistemi (SSS) tutulumu mevcutken, 1 hastada $(\% 4,5)$ parankim dışı SSS tutulumu ve 1 hastada $(\% 4,5)$ periferik sinir sistemi tutulumu mevcuttu. Parankimal tutulumu olan 20 hastanın 16'sinda (\%80) beyinsapı, diensefalon ve/veya bazal gangliyon tutulumu mevcutken, 9 hastada (\%45) hemisferik tutulum, 1 hastada (\%5) meningial tutulum ve 3 hastada (\%15) spinal kord tutulumu mevcuttu. 1 hasta enfeksiyon nedeni ile kaybedildi. 21 hastanın 16'sının $(\% 76,1) 3$. Ay takip verisi mevcuttu. 5 hastanın nörolojik muayenesi normal $(\% 31,25), 1$ hastada $(\% 6,25)$ sadece duyusal bulgular mevcut, 7 hastada $(\% 37,5)$ belirti ve bulgularda kısmi düzelme olup mobilize iken, 3 hasta $(\% 18,75)$ ağır sekelle immobildi.

Sonuç: BH'da nörolojik tutulum farklı klinik tablolar şeklinde ortaya çıkabilmektedir. NBH'da yüksek morbidite ve mortalite riski, erken ve doğru tedavinin önemi akılda tutularak BH olan hastaların nörolojik belirti ve bulguları dikkatle değerlendirilmelidir.

Anahtar kelimeler: Behçet hastalığı, nöro-Behçet, nörolojik tutulum

DOI: 10.5798/dicletip.755722

Correspondence / Yazışma Adresi: Sibel Gazioglu, Karadeniz Teknik Üniversitesi Tıp Fakültesi, Nöroloji Anabilim Dall, 61080 Trabzon, Türkiye e-mail: sibelgazioglu@hotmail.com 


\title{
Clinical Characteristics in Neuro-Behcet's Disease
}

\begin{abstract}
Objective: Neurological involvement in Behcet's disease (BD) is rare, although it is one of the main cause of morbidity. The aim of this study was to investigate the clinical and radiological characteristics of Neuro-Behçet's disease (NBD).

Methods: Demographic and clinical features of 22 patients with NBD diagnosed at neurology department between January 2011 and December 2017 were reviewed retrospectively.

Results: The mean age of the patients was $39.18 \pm 12.25$ years and male to female ratio was 1 . Average disease duration before the onset of neurological involvement was $8.95 \pm 4.28$ years. Twenty patients $(90.9 \%)$ had parenchymal central nervous system (CNS) involvement, one patient (4.5\%) had non-parenchymal CNS involvement and one patient (4.5\%) had peripheral nervous system involvement. Sixteen ( $80 \%)$ out of 20 patients with parenchymal involvement had brainstem, diencephalon and / or basal ganglion, 9 $(45 \%)$ had hemispheric, one (5\%) had meningeal and three (15\%) had spinal cord involvement. One patient died because of infection. $16(76.1 \%)$ out of 21 patients had 3 month follow-up data. Neurological examination was unremarkable in five patients (31.25\%), one patient (6.25\%) had only sensory signs, seven (37.5\%) had partial improvement in symptoms and signs and were mobile, while three $(18.75 \%)$ were immobile with severe sequelae.
\end{abstract}

Conclusion: Neurological involvement in BD may present with various clinical manifestations. The neurological symptoms and signs of patients with BD should be carefully evaluated, keeping in mind the high risk of morbidity and mortality in NBH and the importance of early and correct treatment.

Keywords: Behçet's disease, neuro-Behcet, neurological involvement.

\section{GíRiş}

Behçet Hastalı̆̆ (BH) 1937 yılında Ord. Prof. Dr. Hulusi Behçet tarafından tanımlanan, kronik alevlenme ve remisyon dönemleri ile seyreden multisistemik inflamatuar bir hastalıktır ${ }^{1-5}$. Başlangiçta tekrarlayan oral aftöz ülserasyonlar, genital ülserasyonlar ve üveit ile karakterize bir tablo olarak tanımlanmış olup, bunların dışında eklem, pulmoner, gastrointestinal, ürogenital, kardiak, vasküler ve nörolojik tutulumlar da izlenebilmektedir ${ }^{1,3-}$ 5. Behçet hastalığı tanısı için oral afta ek olarak genital ülser, göz bulguları, deri lezyonları veya paterji testi pozitifliği durumlarından en az

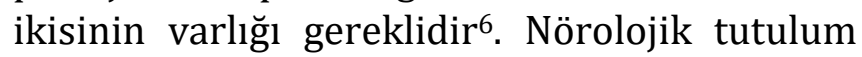
BH'da morbidite ve mortalitenin en önemli sebeplerinden biridir ${ }^{2,7}$. Behçet hastalığında nörolojik tutulumun genellikle diğer sistemik bulguların ortaya çlkmasından sonraki 3-6 yl içerisinde görüldüğü bildirilse de nadiren ilk tutulum bulgusu olarak da görülebilmektedir2,7${ }^{9}$. Behçet hastalığında nörolojik tutulumda ana hedef santral sinir sistemi (SSS) olup parankimal veya non-parankimal tutulum şeklinde görülebilmekte ve nörolojik tutulum bulguları çok farklı klinik tablolar şeklinde ortaya çıkabilmektedir $1,2,5,7$.

Behçet hastalığında nörolojik tutulumun tanısı için kesin bir tanı kriteri veya tek bir tanısal test yoktur ${ }^{2,9}$. Ancak önerilen tanısal kriterler $\mathrm{BH}$ tanı kriterlerini karşılayan bir hastada başka bir sistemik veya nörolojik hastalık veya tedavi ile açıklanamayan nörolojik belirtilerin varlığı ile birlikte nörolojik muayene veya beyin ve/veya spinal manyetik rezonans görüntüleme (MRG) ve elektrofizyolojik incelemeler gibi görüntüleme yöntemleri ve/veya beyin omurilik sıvısı (BOS) incelemesi gibi yardımcı tanısal testlerde objektif anormalliklerin saptanması gerekliliğidir ${ }^{5}$. Spesifik bir klinik ve radyolojik bulgusu olmaması nedeni ile NöroBehçet hastalığı (NBH) tanısında klinik şüphe ve farkındalık çok önemlidir.

$\mathrm{Bu}$ çalışmada nöroloji kliniğinde NBH tanısı alan olguların klinik ve radyolojik özelliklerinin retrospektif olarak araştırılması ve tedavi edilmezse mortalite oranları yüksek olabilecek NBH'da ortaya çlkabilecek klinik tablolar açısından farkındalığın artması amaçlanmıştır. 


\section{YÖNTEMLER}

Ocak 2011- Aralık 2017 tarihleri arasında nöroloji kliniğinde NBH tanısı alan 22 hasta retrospektif olarak çalışmaya dahil edilmiştir. Behçet hastalığı tanı kriterleri olarak Uluslararası Behçet Hastalığı Çalışma Grubu kriterleri (1990) kullanılmıştır6. Bu kriterlere göre, oral afta ek olarak genital ülser, üveit, deri lezyonları veya paterji testinden en az ikisi olmalıdır. NBH tanısı için ise BH tanısı ve MRG, beyin omurilik sıvısı (BOS) incelemesi veya elektrodiagnostik inceleme gibi yardımcı tanısal testlerde uyumlu anormallik tespit edilen nörolojik belirti ve bulgular ve bașka bir etiyolojik nedenle bu belirti ve bulguların açıklanamaması şeklinde kabul edilmiștir ${ }^{5}$. İzole baş ağrısı veya baş dönmesi şikayeti olup yardımcı tanısal metodlar ile uyumlu bir anormallik tespit edilmeyen 6 hasta NBH olarak değerlendirilmeyerek çalışma dışı bırakılmıştır.

Hastaların demografik özellikleri, BH'a ait klinik bulguları (oral aft, genital ülser, papülopüstüler lezyonlar, eritama nodozum, göz ve diğer sistem tutulum bulguları) ve nörolojik tutuluma ait klinik belirti ve bulguları, paterji testi sonucu, HLA B51 pozitifliği, hastalık süresi, nörolojik belirti ve bulguların ortaya çıkma süresi, MRG, elektromyografi ve diğer yardımcı tanısal testlerin sonuçları, tedavi ve takip verileri kayıt edilmiştir. Hastaların MRG bulguları gözden geçirilerek parankimal ve nonparankimal tutulum varlığ $\mathrm{l}$, parankimal lezyonların lokalizasyonu, kontrastlanma özellikleri, serebral ven trombozu (SVT) veya diğer damarsal anormalliklerin varlığ değerlendirilmiştir.

Tüm istatistiksel analizler "SPSS for Windows 16" programı kullanılarak yapıldı. Tanımlayıcı istatistikler uygulanarak bulgular hasta sayısı, yüzde, ortalama, standart sapma ve ortanca biçiminde sunulmuştur. Çalışmanın tıbbi etik açısından uygun olduğuna dair etik kurul onayı 2020/32 nolu protokol numarası ile 28.01.2020 tarihinde Karadeniz Teknik Üniversitesi Etik Kurul onayı alınmıștır.

\section{BULGULAR}

Çalışmaya dahil edilen 22 hastanın 11'i kadın (\%50), 11'i erkek (\%50) idi. Hastaların yaş ortalaması 39.18 \pm 12.25 olup, yaş aralığ $20-65$ yaş idi. Hastaların 20'sinin (\%90.9) bilinen BH tanısı mevcutken, 2 hasta (\%9) nörolojiye başvuru sonrasında $\mathrm{BH}$ tanısı aldı. Bilinen $\mathrm{BH}$ tanısı olan hastaların BH tanısı aldıklarında yaş ortalamaları $31.78 \pm 10.3 \quad(16-48$ yaş aralığı) olup, NBH gelişimine kadar geçen ortalama hastalık süresi $8.95 \pm 4.28$ yll (ortanca 8.5 yll; aralık 2-20 yll) idi.

Hastaların hepsinde oral aft öyküsü mevcuttu. 18 hastada $(\% 81,8)$ genital ülser, 19 hastada $(\% 86,4)$ üveit, 11 hastada (\%50) eritema nodozum, 9 hastada $(\% 40,9)$ eklem tutulumu, 1 hastada $(\% 4,5)$ tromboflebit, 1 hastada $(\% 4,5)$ derin ven trombozu ve 1 hastada $(\% 4,5)$ pulmoner emboli öyküsü mevcuttu. Paterji testi uygulanmış olan $17(\% 77,2)$ hastanın 14'ünde $(\% 82,3)$ testin sonucu pozitifti. HLA-B51 bakılmıș olan $15(\% 68,1)$ hastanın 5'inde $(\% 33,3)$ HLA-B51 pozitifti.

Hastaların başvuru sırasında nörolojik belirti ve bulguları değerlendirildiğinde; 12 hastada $(\% 54,5)$ baş ağrısı, 9 hastada $(\% 40,9)$ yürümede dengesizlik, 11 hastada (\%50) motor ve 6 hastada $(\% 27,3)$ duyusal belirti ve bulgular, 8 hastada $(\% 36,4)$ dizartri ve/veya disfaji, 7 hastada $(\% 31,8)$ çift görme ve 3 hastada $(\% 13,6)$ bilinç veya davranış değişikliği mevcuttu.

Hastaların hepsinin beyin ve spinal MRG'i mevcuttu. 22 hastanın 20'sinde (\%90,.9) parankimal SSS tutulumu mevcuttu. Parankimal SSS tutulumu olan 20 hastanın beyin MRG'de 13 hastada (\%65) beyin sapında, 3 hastada (\%15) bazal gangliyonlarda, 5 hastada (\%25) diensefalonda, 9 hastada (\%45) serebral hemisferlerde lezyon mevcuttu. 20 hastanın 16 'sında (\%80) beyinsapı, diensefalon ve/veya 
bazal gangliyon tutulumu mevcuttu. Hemisferik tutulumu olan 9 hastanın 7'sinde aynı zamanda beyin sapı veya diensefalonda tutulumu da mevcuttu. 1 hastada (\%5) meningial tutulum ve 3 hastada (\%15) spinal kordda lezyon mevcuttu. Parankimal tutulumu olan 20 hastanın 9'unda (\%45) kontrastlı serilerde kontrast tutulumu mecvuttu. 1 hastada $(\% 4,5)$ parankim dişı NBH tutulumu olarak SVT mevcuttu. 1 hastada $(\% 4,5)$ periferik sinir sistemi tutulumu mevcuttu. Tablo 1'de NBH'larının demografik, klinik ve radyolojik özellikleri gösterilmiştir. Resim 1'de örnek bir vakanın akut atak sırasında ve tedavi sonrası MRG'i görülmektedir.

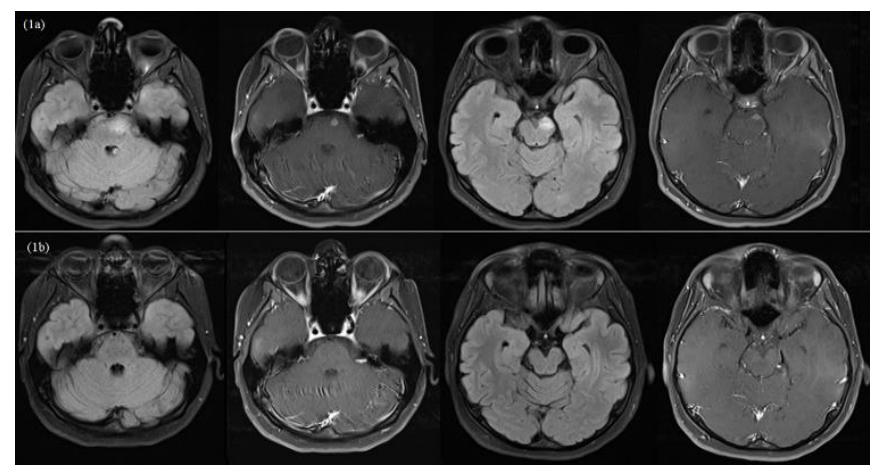

Resim 1. Kraniyal MRG aksiyel (FLAIR ve kontrastlı T1) kesitlerde sol serebral pedinkül ve pons anteriorunda kontrast tutulumu olan lezyon tedavi öncesi (1a) ve sonrası (1b) görülmektedir.

Hastaların tümünde atak döneminde 3-10 gün arası değişen sürelerde pulse doz steroid tedavisi ve 4 hastada $(\% 18,2)$ ek siklofosfamid tedavisi, dural sinüs trombozu olan 1 hastada ek olarak antikoagülan tedavi uygulanmış olup, hastanede yatarken 1 hasta $(\% 4,5)$ enfeksiyon nedeni ile kaybedilmiştir. Hastaların hepsinde akut tedavinin ardından uzun sürede yavaş bir şekilde azaltılan steroid dozu ile birlikte, 19 hastada azotiyoprin ve 18 hastada kolşisin idame tedavisi devam edilmiş olup, 1 hastada ilk ataktan 1 yll sonra, 1 hastada da 8 yll sonra olmak üzere toplam 2 hastada rekürrens gözlenmiştir. Taburcu olan 21 hastanın 16'sının $(\% 76,1)$ 3. Ay takip verisi mevcut olup, 5 hastanın nörolojik muayenesi normal $(\% 31,25)$, 1 hastada $(\% 6,25)$ sadece duyusal bulgular

mevcut, 7 hastada $(\% 37,5)$ belirti ve bulgularda kısmi düzelme olup mobilize iken, 3 hasta $(\% 18,75)$ mobilizasyonu engelleyen ağır sekele sahipti.

Tablo I: Nöro-Behçet hastalarının demografik, klinik ve radyolojik özellikleri

\begin{tabular}{|c|c|}
\hline \multicolumn{2}{|l|}{ Demografik özellikler } \\
\hline Cinsiyet, E/K oranı & $1(11 / 11)$ \\
\hline Yaș, (ortalama $\pm S S$ ) & $39.18 \pm 12.25$ \\
\hline $\begin{array}{l}\text { Nörolojik tutulum öncesi hastalık süresi, yl } \\
\text { (ortalama } \pm \text { SS) }\end{array}$ & $8.95 \pm 4.28$ \\
\hline \multicolumn{2}{|l|}{ Klinik özellikler, n (\%) } \\
\hline Oral aft & $22(100)$ \\
\hline Genital ülser & $18(81,8)$ \\
\hline Üveit & $19(86,4)$ \\
\hline Eritema nodozum & $11(50)$ \\
\hline Eklem tutulumu & $9(40,9)$ \\
\hline Tromboflebit & $1(4,5)$ \\
\hline Paterji testi pozitif* & $14 / 17(82,3)$ \\
\hline HLA B51 (+)* & $5 / 15(33,3)$ \\
\hline \multicolumn{2}{|l|}{ Nörolojik belirti ve bulgular } \\
\hline Baş ağrısı & $12(54,5)$ \\
\hline Yürümede dengesizlik & $9(40,9)$ \\
\hline Motor belirti ve bulgular & $11(50)$ \\
\hline Duyusal belirti ve bulgular & $6(27,3)$ \\
\hline Dizartri/disfaji & $8(36,4)$ \\
\hline Çift görme & $7(31,8)$ \\
\hline Bilinç/davranış değişikliği & $3(13,6)$ \\
\hline \multicolumn{2}{|l|}{ Sinir sistemi tutulum bölgesi, n (\%) } \\
\hline Parankimal SSS tutulumu & $20(90,9)$ \\
\hline Parankim dışı SSS tutulum (SVT) & $1(4,5)$ \\
\hline Periferik sinir sistemi tutulumu & $1(4,5)$ \\
\hline \multicolumn{2}{|l|}{ MRG'de lezyon lokalizasyonu, n (\%) \# } \\
\hline Beyin sapı & $13(65)$ \\
\hline Bazal gangliyon & $3(15)$ \\
\hline Diensefalon & $5(25)$ \\
\hline Serebral beyaz cevher & $9(45)$ \\
\hline Meninks & $1(5)$ \\
\hline Spinal kord & $3(15)$ \\
\hline
\end{tabular}




\section{TARTIŞMA}

Behçet hastalığında nörolojik tutulum sıklığı çalışmaların popülasyon ve dizayn farklılıkları nedeni ile \%2,3 ile \%49 arasında geniş bir aralıkta değișen oranlarda bildirilse de büyük serilerde yapılmış prospektif çalışmalarda siklık genellikle \%5-15 arasında görülmüştür1,2,5,8-10. Klasik olarak NBH'nın ortaya çıkma yaşı 20-40 yaşları olup genel popülasyonda hem hastalık hem de nörolojik tutulum erkeklerde kadınlardan daha sık görülmektedir2,4,5,7-10. Çalışmamızda kadın ve erkek hasta sayısı eşit olup bunun muhtemel nedeni çalışmanın hem hastane temelli olması hem de kısıtlı bir popülasyonda yapılmıș olmasıdır. Behçet hastalığında nörolojik tutulum genellikle diğer sistemik bulguların ortaya çıkmasından sonraki ilk 3-6 yıl içerisinde görülse de çalışmamızda ortalama 8.5 yll olup, literatüre göre daha uzun bulunmuştur2,5,8,10. BH'da hastaların yaklaşık \%6'sında nörolojik tutulumun ilk tutulum bulgusu olabileceği de bildirilmiştir ${ }^{2}$. Buna rağmen genelde ilk olarak nörolojik belirti ve bulgularla başvuran olgularda çok iyi bir sorgulama ile diğer bulguların da olduğu görülebilmektedir ${ }^{5}$. Çalışmamızda da her ne kadar 2 hasta (\%9) nörolojik belirti ve bulguların gelişiminden sonra BH tanısı alsa da bu hastaların ikisinde de geçmişte oral aft ve üveit, birinde de genital ülser öyküsü olduğu gözlenmiştir.

Behçet hastalığında nörolojik tutulumda ana hedef SSS olup, parankimal veya nonparankimal tutulum olarak sinıflandırılan iki ana şekilde görülebilmektedir ${ }^{1-5,7}$. Parankimal lezyonlar beyin sapı, serebral hemisfer, spinal kord tutulumu veya meningoensefalit şeklinde görülebilirken, non-parankimal lezyonlar ise çoğunlukla büyük kan damarları tutulumu şeklinde olup SVT, serebral damarlarda stenoz, anevrizma ve/veya diseksiyon şeklinde şeklinde ortaya çıkabilir. Daha nadiren nöropsikyatrik Behçet sendromu, akut meningial sendrom, beyin tümörüne benzer tutulum, optik nöropati veya periferik nöropati, mononöropati multipleks, myopati ve myozit gibi farklı klinik tablolar şeklinde de görülebilmektedir ${ }^{2,3,5,7}$. BH'da nörolojik tutulumu olan hastaların yaklaşık \%70-80'i parankimal SSS tutulumu şeklinde olup genellikle beyin-sapı diensefalik bölgeyi etkilemektedir ${ }^{1,2,4}$. Bizim çalışmamızda da hastaların \%90'ında parankimal SSS tutulumu mevcutken, sadece 1 hastada parankim dışı SSS tutulumu olarak SVT ve 1 hastada periferik sinir sistemi tutulumu mevcuttu. Çalışmamızda SVT sıklığı literatüre göre daha az görülse de, SVT'nin SSS tutulumu olan olgularının yaklaşık \%20'sinde görülen ikinci en sık nörolojik tutulum formu olduğu bilinmektedir ${ }^{1,2,4}$. Periferik nöropati ise NBH'da nadir görülen bir bulgu olup Al- Araji ve ark.'nın derlemesinde sıklığı \%0,8 olarak bildirilmiştir ${ }^{2}$. Az sayıda hasta ile küçük merkezlerde yapılan çalışmalarda muhtemelen çalışma popülasyonu ile ilişkili olarak bizim çalışmamıza benzer şekilde daha yüksek oranlar da bildirilmiştir ${ }^{10,11 .}$

Behçet hastalığında en sık görülen nörolojik belirti baş ağrısı olmasına karşın, bu ağrıların büyük oranda nörolojik tutulumdan bağımsız primer baş ağrıları veya diğer yapısal olmayan baş ağrıları olduğu bildirilmiştir ${ }^{1,5,11-14}$. NBH klinik özelliklerinin değerlendirildiği bu çalışmada izole baş ağrısı olan ve NBH tanısı almayan hastalar çalışmaya dahil edilmemiştir. İzole baş ağrısı varlığında ileri incelemeler yapılmadan NBH tanısı konulmamasına karşın BH'da baş ağrısı dikkatli bir şekilde değerlendirilmelidir. Çünkü BH'da diğer nörolojik tutulumlarda da baş ağrısının sık bir belirti olarak karşımıza çıktığı bilinmektedir1,5,9,12-14. Bizim çalışmamızda da NBH tanısı alan hastalarda en sık belirtinin hastaların yarısından fazlasında görülen, diğer nörolojik belirtilere eşlik eden baş ağrısı olduğu görülmüştür. 
NBH'da SSS tutulumunda tipik klinik tablo bilinç ve/veya davranış değişikliği ile birlikte veya olmaksızın ortaya çıkan kraniyal sinir tutulumları, dizartri, kortikospinal bulgular, serebellar bulguların görülebildiği subakut beyin sapı tutulumu şeklindedir3,5,9,10,14. Her ne kadar en sık beyin sapı tutulumu görülse de diğer nörolojik tutulum bulguları mutlaka akılda tutulmalıdır3,5. Bizim çalışmamızda da baş ağrısını takiben sıklık sırasına göre görülen nörolojik belirti ve bulgular motor belirti ve bulgular, yürümede dengesizlik, dizartri/disfaji, çift görme, duyusal belirti ve bulgular ve bilinç ve davranış değişikliği idi.

NBH'da beyin MRG'sinde karakteristik lezyon beyin sapında özellikle orta beyin ve ponstan diensefalon ve bazal gangliyonlara uzanan T2'de hiperintens ve T1 'de hipo/izointens, merkezi küçük bir kontrast tutulumu görülebilen lezyonlardır. Bunun yanısıra subkortikal, periventriküler beyaz cevher lezyonları da görülebilir1,2,4,5,15. Hemisferik lezyonlar genellikle beyin sapı ve diensefalik lezyonlarla birlikte görülmektedir ${ }^{5}$. Bizim çalışmamızda literatüre benzer șekilde en sık MRG bulgusu parankimal NBH'nın yaklaşık \%80'ine görülen beyinsapı, diensefalon ve/veya bazal gangliyon tutulumu olup, hemisferik lezyonu olan 9 hastanın 7'inde de aynı zamanda beyin sapı tutulumu da mevcuttu.

NBH'nın tedavisinde büyük kontrollü çalışmalar bulunmamakla birlikte çoğunlukla uygulanan tedavi akut dönemde erken başlanan yüksek doz steroid tedavisini takiben uzun sürede yavaş azaltılan steroid ile birlikte kullanılan oral immünsupresif ajanlar şeklinde yönetilmektedir ${ }^{1-4}$. NBH'da klinik seyir ve prognoz değișken olup genellikle vakaların 2/3'ünün ilk ataktan steroid tedavisi ile düzeldiği ve yaklaşık \%30 hastada tedaviye rağmen progresif nörolojik kötüleşme olduğu bildirilmiştir ${ }^{2,4}$. Çalışmamızda da 1 hastada mortalite görülürken, 3. Ay takip verisi olan hastaların yaklaşık \%40'ında tama yakın düzelme, \%40'ında kısmi düzelme ve yaklaşık \%20'sinde ise ağır sekel görülmüştür.

Çalışmamız az sayıda hasta ile yapılmıș, retrospektif, hastane temelli bir çalışma olması nedeni ile hasta popülasyonunun dağılımda yanlılık ve takip verilerinde kayıp olabileceği düşünülmektedir. Ancak yine de NBH'nın klinik ve radyolojik bulgularını yeniden gözden geçirmek açısından bulgularımız yararlı olacaktır.

Morbidite ve mortalitesi yüksek olan NBH'da erken ve doğru tedavinin önemi akılda tutularak BH olan hastaların nörolojik belirti ve bulguları dikkatle değerlendirilmelidir. Ayrıca her ne kadar nadir de olsa nörolojik tutulumun BH'nın ilk bulgusu olabileceği unutulmamalı ve özellikle akut/subakut şekilde beyin sapı tutulum bulguları ile başvuran hastalarda veya SVT vakalarında BH belirti ve bulguları mutlaka araştırılmalıdır.

Etik Kurul Kararı: Çalışmanın tıbbi etik açısından uygun olduğuna dair etik kurul onayı 2020/32 nolu protokol numarası ile 28.01.2020 tarihinde Karadeniz Teknik Üniversitesi Etik Kurul onayı alınmıştır.

Çıkar Çatışması Beyanı: Yazarlar çıkar çatışması olmadığını bildirmişlerdir.

Finansal Destek: Bu çalışma her hangi bir fon tarafından desteklenmemiştir.

Declaration of Conflicting Interests: The authors declare that they have no conflict of interest.

Financial Disclosure: No financial support was received.

\section{KAYNAKLAR}

1. Akman-Demir G, Saip S, Siva A. Behcet's Disease. Curr Treat Options Neurol. 2011; 13: 290-310.

2. Al-Araji A, Kidd DP. Neuro-Behcet's disease: epidemiology, clinical characteristics, and management. Lancet Neurol. 2009; 8: 192-204. 
3. Kurtuncu M, Tuzun E, Akman-Demir G. Behcet's Disease and Nervous System Involvement. Curr Treat Options Neurol. 2016; 18: 19.

4. Miller JJ, Venna N, Siva A. Neuro-Behcet disease and autoinflammatory disorders. Semin Neurol. 2014; 34: 437-43.

5. Siva A, Altintas A, Saip S. Behcet's syndrome and the nervous system. Curr Opin Neurol. 2004; 17: 347-57.

6. Criteria for diagnosis of Behcet's disease. International Study Group for Behcet's Disease. Lancet. 1990; 335: 1078-80.

7. Peno IC, De las Heras Revilla V, Carbonell BP, et al. Neurobehcet disease: clinical and demographic characteristics. Eur J Neurol. 2012; 19: 1224-7.

8. Ideguchi H, Suda A, Takeno M, et al. Neurological manifestations of Behcet's disease in Japan: a study of 54 patients. J Neurol. 2010; 257: 1012-20.

9. Yoon DL, Kim YJ, Koo BS, Kim YG, Lee CK, Yoo B. Neuro-behcet's disease in South Korea: clinical characteristics and treatment response. Int J Rheum Dis. 2014; 17: 453-8.
10. Houman MH, Bellakhal S, Ben Salem T, et al. Characteristics of neurological manifestations of Behcet's disease: a retrospective monocentric study in Tunisia. Clin Neurol Neurosurg. 2013; 115: 20158.

11. Gokcay F, Celebisoy N, Gokcay A, Aksu K, Keser G. Neurological symptoms and signs in Behcet disease: a Western Turkey experience. Neurologist. 2011; 17: 147-50.

12. Kale N, Agaoglu J, Icen M, Yazici I, Tanik O. The presentation of headache in neuro-Behcet's disease: a case-series. Headache. 2009; 49: 467-70.

13. Siva A, Kantarci OH, Saip S, et al. Behcet's disease: diagnostic and prognostic aspects of neurological involvement. J Neurol. 2001; 248: 95-103.

14. Siva A, Saip S. The spectrum of nervous system involvement in Behcet's syndrome and its differential diagnosis. J Neurol. 2009; 256: 513-29.

15. Domaç FM BE, Mısırlı H, Adıgüzel T, Özden T, Ertorun A. Nöro-Behçet Sendromlu Olgularda Kraniyal Manyetik Rezonans Görüntüleme Bulguları. Türk Nöroloji Dergisi. 2010; 16: 21-6. 